Published in final edited form as:

Qual Health Res. 2012 August ; 22(8): 1114-1125. doi:10.1177/1049732312448543.

\title{
Stress Variances Among Informal Hospice Caregivers
}

\author{
Elaine Wittenberg-Lyles ${ }^{1}$, George Demiris ${ }^{2}$, Debra Parker Oliver ${ }^{3}$, Karla Washington $^{4}$, \\ Stephanie Burt ${ }^{5}$, and Sara Shaunfield ${ }^{1}$ \\ 1 University of Kentucky, Lexington, Kentucky, USA \\ ${ }^{2}$ University of Washington, Seattle, Washington, USA \\ ${ }^{3}$ University of Missouri, Columbia, Missouri, USA \\ ${ }^{4}$ University of Louisville, Louisville, Kentucky, USA \\ 5 University of North Texas, Denton, Texas, USA
}

\begin{abstract}
Care interventions are not routinely provided for hospice caregivers, despite widespread documentation of the burden and toll of the caregiving experience. Assessing caregivers for team interventions (ACT) proposes that holistic patient and family care includes ongoing caregiver needs assessment of primary, secondary, and intrapsychic stressors. In this study, our goal was to describe the variance in stressors for caregivers to establish evidence for the ACT theoretical framework. We used secondary interview data from a randomized controlled trial to analyze hospice caregiver discussions about concerns. We found variances in stress types, suggesting that caregiver interventions should range from knowledge and skill building to cognitive-behavioral interventions that aid in coping. Family members who assume the role of primary caregiver for a dying loved one need to be routinely assessed by hospice providers for customized interventions.
\end{abstract}

\section{Keywords}

caregivers/caregiving; coping and adaptation; end-of-life issues; illness and disease; lifethreatening/terminal; psychosocial issues

\begin{abstract}
The fragmented health care system in the United States leaves the majority of caregiving tasks, including day-today oversight of activities of daily living, pain management, medical finances, and medical history, to unpaid or informal caregivers who are often family members or close friends (Levine, Halper, Peist, \& Gould, 2010). Commonly known in the literature as family caregivers, these individuals function as patient advocates, ensuring their presence during medical consultations and diagnostic tests, and are typically present during difficult prognosis disclosures (Eggly et al., 2006; Levine et al., 2010). Their role in health care management and medical decision making can be even greater when caring for a loved one enrolled in hospice.
\end{abstract}

(C) The Author(s) 2012

Corresponding Author: Elaine Wittenberg-Lyles, University of Kentucky, Markey Cancer Center, 741 S. Limestone, B357 BBSRB, Lexington, KY 40506-0509, USA, elaine.lyles@uky.edu.

Reprints and permission: sagepub.com/journalsPermissions.nav

Declaration of Conflicting Interests

The authors declared no potential conflicts of interest with respect to the research, authorship, and/or publication of this article. 
Under the Medicare benefit in the United States, hospice care is provided to patients with an estimated 6 months or less of life expectancy (Centers for Medicare and Medicaid Services, 2008). Although hospice care can be provided in a number of different care settings (e.g., nursing home, adult family home), $68.6 \%$ of hospice patients in the United States receive care in their place of residence by a family caregiver (National Hospice and Palliative Care Organization, 2010). To facilitate care, regardless of setting, hospice agencies require patients to have an identified caregiver who can work in tandem with the hospice team (Centers for Medicare and Medicaid Services; Lorenz, Asch, Rosenfeld, Lui, \& Etter, 2004). Thus, the family caregiver plays a key role in the decision to elect for hospice care (Wittenberg-Lyles \& Thompson, 2006; Zhang, Zyzanski, \& Siminoff, 2010) and often is responsible for making the final decision to enroll the patient in hospice (Chen, Haley, Robinson, \& Schonwetter, 2003). Given family members' pivotal role in the composite of hospice services, we sought to extend our understanding of their concerns during hospice caregiving.

As family members assume responsibilities for dying loved ones, they share in the patient's illness journey and experience the pain and suffering that can occur at the end of life (Levine et al., 2010; Sherman, 1998). Caregiving tasks are often highly time consuming,

overwhelming, and usually unanticipated or sudden, all of which compound the caregiver's vulnerability to clinical levels of depression (Rivera, 2009). Such psychological distress can compromise the caregiver's immune system and/or increase his or her chance of suffering from coronary heart disease (Rivera). These duties also interfere with work responsibilities, which can create an unsupportive work environment and add more social and emotional stress (Swanberg, 2006). In addition, caregivers report heightened thoughts of guilt associated with attending to their own care needs, resulting in both lack of self-care and depression (Gonyea, Paris, \& de Saxe Zerden, 2008; Sherman).

Although the hospice model situates the patient and family as one unit of care, research consistently highlights the inadequacies of hospice support for caregivers (Hudson, Remedios, \& Thomas, 2010; McNamara \& Rosenwax, 2010). Family caregivers report a need for more information on the patient's illness, treatment options, and side effects, with special attention given to information about physical caregiving techniques (Thielemann, 2000). They report frustration with medical staff in the lack of acknowledgment of the importance of their role and the need for information about pain management (Kimberlin, Brushwood, Allen, Radson, \& Wilson, 2004). Practical support is nearly absent, leaving caregivers with a lack of practically focused information exacerbated by poor methods of dissemination (Bee, Barnes, \& Luker, 2009; Harding \& Higginson, 2003).

Despite these documented deficiencies, few interventions exist that specifically target the hospice caregiver (Bee et al., 2009; Harding \& Higginson, 2003; Hudson et al., 2010). Current caregiver support offered by a hospice agency is commonly limited to respite care, one-on-one education, and/or referral to a support group (Harding \& Higginson). However, these types of generic interventions do not meet every caregiver's needs (Harding \& Higginson). Caregiver needs vary across the illness trajectory (DuBenske et al., 2008) and burden varies based on subjective experiences and social support (Goldstein et al., 2004). It is surmised that the lack of evidence on the effectiveness of caregiver interventions might be the result of global rather than targeted interventions (Harding \& Higginson). However, the use of interdisciplinary team support is proffered to meet caregivers' unique needs (Demiris, Parker Oliver, \& Wittenberg-Lyles, 2009; Harding \& Higginson) and successfully integrate family caregivers and patients into one unit of care. 


\section{Theoretical Framework}

A theoretical framework called ACT, assessing caregivers for team interventions (Parker Oliver, Demiris, Wittenberg-Lyles, \& Porock, 2010), depicts the hospice interdisciplinary team (physician, nurse, social worker, and chaplain) as an external mediator within the caregiving experience. The model calls for the ongoing assessment of the caregiver's background along with primary, secondary, and intrapsychic stressors and ultimately the outcomes of caregiving to design and deliver appropriate customized interventions by the hospice team. This theoretical framework is an extension of the original stress process model of the caregiving experience (Pearlin, Mullan, Semple, \& Skaff, 1990) that has now been modified (Meyers \& Gray, 2001). As the degree of anxiety occurs as a consequence of caregiving, it is counterbalanced by positive experiences gained through support and information from hospice staff. However, limited personal resources and coping strategies can cause psychological complications, triggering anxiety appraisal and coping that can be reduced through the provision of support and information. Understanding the specific stressors of the hospice caregiving experience should inform the design of appropriate interventions, allowing for the customization of support and information provided by the hospice interdisciplinary team. Our goal was to use the ACT model to examine various stress types, specifically primary, secondary, and intrapsychic stressors, to aid in the development of customized intervention tools.

\section{Method}

We drew from a larger pilot randomized clinical trial designed as a noninferiority trial funded by the National Institute of Nursing Research. The goal of the larger project was to demonstrate the feasibility of delivering a problem-solving intervention called ADAPT (attitude, define, alternatives, predict, try) in a two-group intervention study for hospice caregivers (Demiris et al., 2009; Demiris et al., 2010). The intervention is designed to help caregivers be effective in solving problems pertaining to the caregiving experience by (a) adopting a positive orientation to problem solving, (b) carefully identifying the facts associated with the problem, (c) exercising creativity in generating a list of alternative approaches to solving the problem, (d) predicting the consequences of each alternative and selecting the one most likely to be effective, and (e) implementing the selected alternative to solve the problem. In this study we explored digitally recorded discussions of the first step of the problem-solving intervention between hospice caregivers and interventionists in which caregivers were asked to identify and describe the most pressing problems or concerns they faced. The intervention visit was chosen as the site for data exploration because it allowed researchers to capture caregiver responses about any caregiving-related concerns. Data collection for this study was approved by the supporting university's institutional review board.

\section{Setting}

Data were collected from consenting hospice caregivers in two urban hospice programs in the western United States. Both programs were Medicare and Medicaid certified. Total home admissions per year were 2,619 for Hospice Agency A and 1,325 for Hospice Agency B, with an average daily census of 510 and 189 , respectively, and an average length of stay 65.2 days for Agency A and 59 days for Agency B.

\section{Participants}

Participants were hospice caregivers. Caregivers enrolled had to be 18 years or older, have access to a standard telephone line, be without functional hearing loss, have no or only mild 
cognitive impairment, and have at least a 6th-grade education. The data for the study presented here were collected between February 2009 and March 2010.

\section{Procedure}

On admission to hospice, caregivers were presented with the research opportunity by hospice staff. The research coordinator visited interested and eligible caregivers and obtained informed consent. Caregivers were asked to prioritize common concerns using a checklist. In addition, to individualize the intervention material, caregivers were allowed to define problems not included in the list. These discussions were digitally recorded and served as the corpus of data for this study.

\section{Data Analysis}

We used NVivo 8 qualitative data analysis software to analyze intervention discussions between caregivers and interventionists (QSR International, 2008). Initially, three of us (the first, fifth, and sixth authors) listened to five intervention discussions and used the three variables of the ACT model (primary, secondary, and intrapsychic) as a lens for inquiry. During this process it was determined that coding would consist of the following ACT categories: (a) primary stressors-caregiver talk that related to the performance of caregiving tasks; (b) secondary stressors—caregiver talk about the personal impact of performing caregiving tasks; and (c) intrapsychic stressors—caregiver talk about thoughts, feelings, and awareness of the caregiving role. We also clarified and created strict coding categories. Once coding categories were developed, we individually listened to and transcribed caregiver talk in the initial five intervention visits, identifying 48 utterances and achieving intercoder reliability above .85 on all coding categories. In addition, no new categories emerged. With a definitive coding guide established, the fifth author transcribed caregiver talk in the remaining data set and coded talk into one of the three coding categories (primary, secondary, intrapyschic). We then reviewed a portion of the data set $(25 \%)$, and no new themes emerged. Coding validation was verified midway in this process, and coded utterances were blind coded by research team members, yielding .75 intercoder reliability. Members of the research team jointly reviewed transcripts to determine and resolve differences.

Once all the data were coded into the theoretical classes (primary, secondary, intrapsychic), data for each category were inductively analyzed using an iterative process of theme analysis comprising four distinct phases (Creswell, 1998; Strauss, 1987). First, open coding was used to identify unrestricted "chunks" of text suggesting a theme, then identified themes were collapsed or associated. Next, categorizations of talk were clarified, and finally interpretive claims about the categories identified through group discussion were constructed (Lindlof \& Taylor, 2002; Strauss). To establish validity, the first and sixth authors analyzed the data independently and openly discussed and resolved differences. From this process, we discerned themes within primary, secondary, and intrapsychic stressor categories.

\section{Results}

We collected digital recordings of 84 intervention discussions for 81 hospice caregivers ( 3 caregivers had more than one visit to complete Step 2 of the intervention from the larger project). The mean age of patients was 80 years, whereas the mean age of caregivers was 61 years. The majority of patients $(67.9 \%)$ did not have a cancer diagnosis; however, $21 \%$ of patients had a primary or secondary diagnosis of Alzheimer's disease or dementia. Most caregivers and patients were White $(96.3 \%, 95.1 \%)$. An overwhelming majority of caregivers were women (79\%); however, patients were more evenly split, as $61.7 \%$ were 
women and $38.3 \%$ were men. More than half of the caregivers had a postsecondary education, with $24.7 \%$ having some college, $13.6 \%$ having a 2 -year college degree, $29.6 \%$ having a 4-year college degree, $11.0 \%$ having a master's degree, and three caregivers having a doctoral degree. The majority of caregivers were adult children of the patient (43.2\%), and one third of caregivers were the spouse or partner of the patient $(30.9 \%)$. Almost half of caregivers lived with the patient $(49.4 \%)$. In the following section we detail the thematic analysis of primary, secondary, and intrapsychic stressors. Figure 1 illustrates the ACT model with these themes.

\section{Primary Stressors}

Primary stressors emanate from performing caregiving tasks. Caregivers reported taskrelated primary stress from witnessing the patient's decline, experiencing conflict over care with the patient, second-guessing pain management, and receiving unsolicited evaluation from outsiders.

Witnessing decline-Hospice caregivers talked about the difficulty of providing care while witnessing patient decline. Caregivers described patient decline by identifying sudden changes in the patient's ability to perform or participate in activities of daily living, thereby increasing the caregiver's responsibilities. Such quick changes to care routines were considered stressful for caregivers, who often explained that this required additional assistance and accommodations that had not been prearranged. Caregivers were also anxious about handling intermittent crisis care situations such as shortness of breath, difficulty swallowing, and patient fragility.

Primary stress also emerged from observing changes in patient behavior, especially among caregivers providing care for patients with Alzheimer's disease or dementia. Caregivers reported thoughts of loss, as one caregiver whose mother had Alzheimer's disease noted: "It really gets to me to see her because she was extremely sociable, very, very sociable ... and to see her just sitting there is very, very hard." Caring for patients with cognitive loss compounded caregiving and brought additional worry for caregivers. Patient confusion and hallucinations, either disease oriented or as a side effect of medication, created primary stress for caregivers who had to negotiate patient conversations about events and activities that did not take place. For these family members, caregiving became a twofold task: providing physical care and negotiating patient conversations that indicated cognitive loss.

Patient struggles-Patients perceived as uncooperative in the care process created primary stress for caregivers. Anxiety resulted from tensions created between patients who were still able to communicate and be involved in decision making yet relied on caregivers. In patient cases where Alzheimer's disease or dementia was present, caregivers described cognitive loss as an additional stressor in primary care. Caregivers detailed the difficulty of negotiating patient preferences alongside their own needs. Patients who refused to take medication, refused medical equipment, or had personal preferences or anxieties created primary stress for caregivers. Anxiety and trepidation also resulted from caregivers who knew that their loved one wanted to be cared for at home but felt they could not do it.

Working with patients who "don't tell us everything" proved to be a primary stressor for caregivers, especially as it related to pain. Caregivers were distressed to find that their loved ones were not always open about pain and often found instances where patients did not tell health care staff about issues or problems. A family caregiver summarized this difficulty in her experience with her mother who had dementia and was on hospice in a nursing home setting: 
The next day, the ER [emergency room] doctor said she had a flaming bladder infection. I have seen her writhe and scream in pain, and then the nurse, or the LVN [licensed vocational nurse] at the nursing home will say, "Are you in pain?" And she'll go, "No." She'll never say that she's in pain. You can't rely on those "noes" and "yeses."

This caregiver's concern for quality care was exacerbated by her mother's disease. She had the ability to communicate and thus regulated information; however, information was often inaccurate and made the caregiver's task more difficult and stressful.

Second-guessing pain management-Family caregivers who were providing hospice care at home also reported concern about pain, characterizing primary stress as a result of the trepidation of providing pain management. The amount of pain medication prescribed to patients as well as the ability to properly administer the correct dosages caused caregivers stress and concern. For example, in his account of providing morphine to his wife, one caregiver noted, "It was an eyedropper thing, and I'd never really used an eyedropper. And the level of the eye-dropper kept going way up and way down. I didn't want to give her too much or too little." For him, primary stress was directly related to pain-management skills. In addition, caregivers of patients with Alzheimer's disease or dementia noted that it was hard to discern when patients were in pain and when to administer medication.

Outsiders-For at-home caregivers, unsolicited critiques of care were considered offensive and added stress to an already volatile environment. Critiques came from individuals outside the caregiver's primary support system, including family members, friends, and health care staff not associated with hospice. One caregiver recalled,

This woman flared at me, and made an accusation of my not caring for my mother properly, which threw me totally for a loop because since Mom has been on hospice, we've worked with hospice.... She chooses to sleep, so I don't disturb her until dinner time, but this woman took it as not caring properly to let my mother sleep.

Additional primary stress from outsiders included disrespectful behavior from family members who were insincere about visits or whose communication provoked the patient ("I wish they would just be nice to him. Just be nice, be kind."). "Outsider" involvement resulted in additional care responsibilities that affected primary stress.

Alternatively, family members of hospice patients in a nursing home setting described worry and anxiety resulting from their roles as outsiders in the care process. For these caregivers, their role was to oversee the quality of care provided in the institutionalized setting, and many of them fretted over communication with staff. When calling to check on her mother, one caregiver explained, "She choked again is what they said when I called. Well I never knew she choked the first time." Because these caregivers were not charged with actual care tasks, their primary stress came from delays in information, lack of understanding about hospice and end-of-life care, and skepticism about care provision.

\section{Secondary Stressors}

Secondary stressors resulted from the impact of providing primary care and were considered by caregivers to be more personal in nature, centering around the impact of the caregiving role on their personal lives and routines. This included stress emanating from family communication patterns, sleep deprivation caused by worry, financial headaches, and caregivers' propensity to rationalize guilty thoughts. 
Family communication patterns-Family communication patterns and family relationships were brought to the forefront of the family system by the health care crisis of a family member. Often, the level of family participation and involvement created secondary stress for caregivers. Although caregivers in this study depicted their role as primary attendant to the patient, they also described how family communication and family practices created additional stress. Several caregivers described being abandoned by their family and being told, "You're there. You deal with it. You're the durable power of attorney." This sense of abandonment not only was hurtful but also left them with limited resources and support. Family communication patterns also depicted historically hostile relationships between family members, and as a result caregivers described limiting family participation: "I'm totally avoiding them because they bring on stress to me. They ask me stupid questions. They give me stupid ideas."

When caregiving required two family members to engage in shared tasks and negotiate primary care responsibilities, secondary stress evolved from the family members' relationship. Caregivers reported the difficulty of sharing care tasks equally and described family structure as an inhibitor to care provision. An adult daughter and her father had differences of opinion regarding pain medication for her mother:

In his mind, he thinks that if she doesn't take all the morphine and stuff maybe she'll get better because these drugs are making her worse.... But the bigger picture is why would you want her to suffer like this? Why keep her in agony? And his explanation when I asked him was, "Well, I want to save them for when she gets really bad. If she takes too many now then it won't help her when it gets really bad." Okay, so we'll just make her lay in agony until you deem it's really bad, and then we'll give her the drugs?

Although two family caregivers would appear to be ideal in providing at-home care, secondary stress emerges as family members must collectively make care decisions.

The historical nature of family relationships also added to caregiver strain. Adult children talked about difficulty with parent relationships that were accentuated by care provision and patient dependence. One woman caring for her father described the struggle to provide care:

He was never, never there for my brother, and that just kills me [crying]. And then when my mom got sick, he was just not patient. He would just yell and say mean things, and I couldn't handle it. So now I'm getting it back at him, so I'm saying the mean things to him. And at the time, it makes me feel good, and now I feel guilty.

Long-held family communication patterns remained intact, although some caregivers reported that they "did what I've done my whole life. I don't listen." Others shared animosity and struggled to handle the emotional stress.

Sleep deprivation-The loss of sleep was commonly shared among all caregivers in this study. Sleep deprivation predominantly occurred as a result of nighttime care concerns and duties rather than primary care responsibilities. Worrying about being able to hear the patient at night kept caregivers awake and sleep deprived. Caregivers talked at length about how nighttime care increased anxiety. An adult daughter of one patient described this experience: "Sometimes you get so tired that you're out. And that's a little scary because you need to know. It's like a mom with a baby."

Caregivers also worried about their ability to provide compassionate care, despite feelings of exhaustion and their own need for sleep. In recalling a particularly challenging evening with her mother, a caregiver summarized, 
I was up with her until midnight. She called us in at two [o'clock]. She called us in at four.... She was confused. She was awake and she was up and down, up and down, up and down. So just trying to remain patient with that. So I just wish she would have gone to sleep.

This caregiver's concern was not about her mother's safety or own sleep needs but rather about her own ability to be patient in the way that she interacted with her mother. Secondary stress emerged from sleep deprivation caused by worry over the patient's needs during the night, as well as the caregiver's concern for the provision of loving care when he or she felt tired and exhausted.

Financial headaches-Taking care of the patient's finances often resulted from the family member's designation of power of attorney. This task included a high paperwork volume that added to the caregiver task list, as one caregiver noted:

She has trusts. They have to be managed. She has taxes. They have to be paid. She has bills. They have to be paid. There's just sort of an ongoing stream of ... go to the bank. I have the durable power of attorney, so I have to deal with basically all of her medical bills.

Secondary stress emerged for these caregivers who worried about making financial decisions about how to appropriately manage the patient's money. An adult daughter caring for her father rationalized that he loved rib steak, so she paid to have his teeth fixed "so he can eat rib steak until the end of his life." She described how she labored over this decision, worrying about how it would be perceived by others. Family disagreements also resulted from disputes over the patient's money.

Likewise, stress resulted from lack of money and subsequent concern for housing ("I wonder so often how are we going to be able to keep the house") and the ability to maintain employment while caregiving. Care provision was exacerbated for at-home caregivers who worried about financial security. Outside employment was also a financial stressor, and caregivers felt torn between working to pay for care services and spending time with their loved one. Secondary stress emerged regardless of financial status as caregivers experienced stress from financial tasks or worry about the lack of money.

Rationalizing guilt-Caregivers described thoughts of guilt associated with care decisions. Overall, guilt was expressed as a secondary thought resulting from the emphasis on primary care. The tension between putting effort into primary care vs. spending quality time with the patient at the end of life was evident, as noted by one caregiver: "I guess I could spend more time just sitting in there with her, but other things don't get done that need to get done." The desire to spend time with patients was recognized by caregivers but considered less important than fulfilling patient needs.

The emphasis on primary care was also used to rationalize care choices, especially when patients were placed in a nursing home. The decision to place a loved one outside of the home left caregivers with guilty thoughts. The adult child of one patient described her decision to move her mother to a nursing home:

I took care of her for four years, but I couldn't leave her alone. And she needed more care and I had work so I couldn't do that anymore. So that part I feel guilty [about] because I couldn't just quit my job and hire someone to help me take care of her with me.

In the absence of primary care duties, caregivers described visiting as a way of performing their caregiving role. An adult grandchild overseeing care for her grandmother noted, "Right 
now I have to find time to get over and see my grandmother and spend time with her ... that's a dilemma for me." Caregivers for both at-home and nursing home patients talked about guilt as the result of choices made in the care process that were rationalized as unavoidable and unresolvable.

This perspective of guilt, considered a natural part of the caregiving experience, also detracted from their ability to reach out to social support networks. Caregivers felt guilty talking with others about the stress of caregiving: "Sometimes I feel embarrassed to talk to people about it, because I think that, I believe people are getting tired. They don't want to hear what I'm saying. I don't want people to feel like they have to." It was common for caregivers to share that they would "hate to impose on somebody" by asking for help or talking about the experience. Guilt resulted from placement decisions, care demands that limited the ability to spend casual and quality time with patients, and the shared perception that discussing caregiver stress with others was inappropriate.

\section{Intrapsychic Stressors}

Intrapsychic stressors represented the caregiver's awareness and thoughts about the role of caregiving. This stressor was characterized by self-imposed role expectations, role mastery related to hospice acceptance, the tendency to neglect emotions, and anticipatory grief during caregiving.

Role expectations-Caregivers clearly articulated their personal values and beliefs about caregiving, revealing their own mental yardstick used to set role expectations. Some saw their position defined by family obligation, as illustrated by an adult daughter who explained why she and her brother were overseeing their mother's care: "We just feel like it's what we're supposed to do. We want to care for our parents and they asked not to go to a nursing home." Similarly, many female caregivers conveyed that being a caregiver was "a gift" that had been part of their personality: "I am a caregiver. I always have been since I was a little girl."

Such positive attributions to fulfilling the caregiving role established a sense of confidence and comfortableness with role expectations. An adult child caring for her father summarized her experience thus far: "When the time comes and he goes, I will be very at peace with myself because I will know that I did everything that I could." These caregivers described their job as a "privilege" and took personal pride in serving as a caregiver, noting that "it makes you feel better, too, knowing that you're taking care of what you can the best that you can." Although they understood that the task at hand would be difficult, they were "willing to be that person," recognizing that they would "be glad afterwards" as their efforts would result in "really positive closure."

Positive attributes to fulfilling the caregiver role revealed high role expectations, however. A woman caring for her father summarized the experience: "This is basically, I feel like I've done so much caregiving. I mean this has been a four-year, four years before this, and in the end, I just want to finish well." Although caregivers were "happy to do it" they often placed self-imposed standards for performance on their expectations for caregiving. These expectations were often a source of stress.

Role mastery-Role mastery involved the ability to handle difficult or crisis situations and remain calm. Long-time caregivers (more than a year of caregiving experience) described their efficiency in being able to problem solve and act quickly. When having problems with his 101-year-old father, an adult son who had been providing care for 14 years reported, "It doesn't freeze me, it doesn't stop me. The calamity that's precipitating, it doesn't cause me to lock up." Role mastery was also evidenced by a demonstrated 
proficiency in medical terminology and comfortableness about pain-management responsibilities. Searching to find the right pain medication, a daughter caring for her father described how she accomplished this:

He complains when he's laying in bed, when he lays down at night. That's when he complains about pain. So it's Tylenol during the day. Morphine at night. Then we try various cocktails like temazepam and lorazepam [anxiety-reducing drugs]. "Pam" cocktails, we call them [laughing]. What we figured out is there's not [a] magic cure. It's just different everyday. So we just kind of go with the flow and see how he feels.

This caregiver talked with ease about manipulating medication to achieve the desired outcome, suggesting that she was comfortable with this responsibility and process.

Although caregivers might be secure in their caregiving role (if not, then they experience primary stress, because role mastery has not been accomplished), intrapsychic stress emerges from awareness of the hospice context. As caregivers are introduced to and educated about hospice philosophy and encouraged to assist patients in allowing a natural death, they also realize the uncertain time frame ("the wild ride") that accompanies terminal prognosis. The spouse of one patient described what this was like for her:

Obviously most people don't want to know when [someone will die], but in this situation, we pretty much do. And most people don't want to know when.

Obviously, when it takes a long time, when you lose somebody in bits and pieces, it's a death of a thousand deaths.

Role mastery is obtained through this understanding, and although final patient arrangements have been made such as funeral planning, inherent stress emerges while waiting "for the finality of it all." An unknown time frame for care provision, not knowing if it will be "months or years," leaves caregivers hoping that they will be "strong enough to be there to help."

Role mastery can also lead to intrapsychic stress for caregivers who shoulder the task of helping the patient come to terms with death. Caregivers were concerned about patients who were struggling to acknowledge that this was the end of their life. The patient's fears created additional pressure for caregivers. One woman struggled with her father's request for assisted suicide, which was legal in their state. Although she was not opposed to him ending his life, as she firmly believed in his right to make the decision, she didn't think she was comfortable being part of it, explaining, "Honestly, I just feel like an accomplice, even though I know it's legal. But it's like driving the getaway car." She had the skills and legal right to accommodate his wishes but grappled with the decision to participate.

Handling emotions-The caregivers' emotional state and ability to handle the emotional side of caregiving were influential to the care process and represented another intrapsychic caregiver stressor. Most typical of the caregiver experience were feelings of anger, resentment, loss, and sadness. Caregivers very eloquently identified their emotional state, some with directness: "I don't even want to take care of him. What does that tell you? I'm angry." The affective state of the caregiver had an impact on the approach to caregiving, as one woman who had been caring for her mother for 9 years explained:

There's days when I have resentment and then there's days when I'm absolutely overjoyed even to clean her diaper. I'm probably a real nut. There's days when I go away and take my days off, and then I come back. I'm so glad to see her and give her a kiss and that she's still alive that it's not hard to clean her diaper. 
Caregivers were aware of this back-and-forth of emotions and how it shaped their ability and proclivity to provide care.

It was common for caregivers to describe a concentrated effort to control or acknowledge a lack of control over their emotions. Overwhelmingly, the "need to give permission" to be emotional was outweighed by the propensity to neglect emotions to facilitate coping. One caregiver noted, "I've gotten very good at putting my emotions on the back burner because right now, it's the only way I can function." Although these thoughts were acknowledged in some cases, it was more common for caregivers to describe compartmentalizing their emotions to focus on primary care. Fewer caregivers talked about being emotional all the time, explaining, "I just tell myself I don't have any control over it. I do what I can." In an extreme case, an adult daughter caring for her mother explained,

I just want to cry all the time. I'm sure it's because my momma's sick, that's why I feel like that. I don't know. It's weird. When I feel depressed, I just want to cry. I don't want to live. Like I want to die.

Caregivers who described the inability to control emotions described high emotional losses and thoughts of sadness and helplessness. The work to control or be preoccupied by uncontrollable emotions characterized intrapsychic stress.

Anticipatory grief-Many caregivers were worried and concerned about what their lives would be like once the patient died, experiencing anticipatory grief during the caregiving process. Anticipatory grief can be experienced when death is expected and involves the thoughts, feelings, and cultural and social reactions associated with the loss of a loved one (National Cancer Institute, 2011). The wife of a patient who had amyotrophic lateral sclerosis for 4 years summarized, "It's four years of grieving I think, too. From day one, we knew what was going to happen. But that never really prepares you for the end." Another spouse caregiver also felt the pain of loss even as she provided care to her husband:

So I guess, letting go and saying okay. I don't know how strong I'm going to be when it comes time for that ... I don't know how I can deal with that, to just let somebody say goodbye. We've been together so long, it's like we're old habits.

The fear of loss, "being without" the patient, and the impact of loss on their lives ("It will change my life dramatically, dramatically") were all considered aspects of caregiving that they did not "know how to handle." A peripheral concern regarding the loss of the patient was the impact on family dynamics. Finally, spousal caregivers were worried about the impact on children in the household following the death of their spouse.

\section{Discussion}

Assessing caregivers for team interventions (ACT) is a theoretical framework that has been proposed as a way to understand caregiver strain and develop mediating and customized caregiver interventions, thus affecting the overall caregiver experience and improving outcomes (Demiris et al., 2009). The ACT model outlines components for caregiver needs assessment, including background context, primary, secondary, and intrapsychic stressors, and outcomes of the caregiving. Our aim in this study was to describe the variances among these stressors, thus advancing the theoretical tenets of the ACT model and targeting specific assessment concerns for caregivers. Overall, the findings in this study confirm that hospice family caregivers are "second-order patients" with their own unique care needs (Sherman, 1998).

From our analyses primary stressors appeared to be those over which the caregivers felt they had the least control, characterized by stress from patient decline, patient care, and pain 
management. These findings also evidence that hospice caregivers are not comfortable with nor do they understand pain-management practices or directions (Parker Oliver et al., 2008). Similar to other studies, caregivers reported problems with patients who resisted treatment as well as difficulty understanding symptom and medical knowledge (Lau et al., 2010). However, primary stress varied between caregivers who had experience with caregiving (e.g., had provided care before or had provided care for some time) and those who were relatively new to the caregiver role. For example, research has shown that caregiving for different diagnoses can yield varying experiences, and those providing care for loved ones with Alzheimer's disease or dementia experience the highest amount of burden and deficit to physical and mental health (Hebert \& Schulz, 2006; Lunney, Lynn, Foley, Lipson, \& Guralnik, 2003). Thus, caregivers should be assessed for "caregiving experience" so that interdisciplinary team members in the clinical disciplines (physician, nurse) can provide appropriate training on pain-management practices, ranging from assessment to medication provision. Educational training about pain management has been found to be effective for both caregivers and patients (Keefe et al., 2005; Kwak, Salmon, Acquaviva, Brandt, \& Egan, 2007).

Secondary stressors were easily identifiable by caregivers and largely dependent on perceived availability of resources. Issues pertaining to family communication practices, sleep deprivation, financial headaches, and rationalizing guilt involved variance in the perceived amount and quality of resources available. Congruent with other findings, a perceived lack of support indicated the presence of secondary stress (McNamara \& Rosenwax, 2010). Caregivers should be assessed to determine the social support networks available as well as family functioning. Prior work has demonstrated that high family functioning positively affects coping (Pruchno, Burant, \& Peters, 1997). Cognitivebehavioral interventions could be especially effective for teaching caregivers how to reduce secondary stress. For example, caregiver quality of life improved and stated anxiety decreased following the completion of a problem-solving intervention (Demiris et al., 2012), and caregivers learned how to obtain closure following a 7-hour course (Kwak et al., 2007).

Intrapsychic stressors shared by caregivers indicated that this stress type is the one over which caregivers have the most control. Findings indicate that having a greater degree of control makes the caregiving situation much more manageable. The data in this study allude to a shift from negative to positive between primary and secondary stressors and intrapsychic stressors. This shift suggests that coping occurs as caregivers learn more about their role. It is possible that caregivers with predominantly primary and secondary stress have a greater need for support and intervention than those with secondary and intrapsychic stress. This claim is supported by findings that family caregivers who resist help ultimately have limited resources and support, resulting in a negative impact on their health and ability to cope (McNamara \& Rosenwax, 2010; Stajduhar, Nickel, Martin, \& Funk, 2008).

Family was a factor in each of the stressor categories. Similarly, prior research has found that families who have a prior history of family communication constraints are more likely to experience family conflict (Kramer, Kavanaugh, Trentham-Dietz, Walsh, \& Yonker, 2009). Of interest, this study adds to the literature on hospice patient pain by depicting the important role and implicit knowledge that family caregivers can contribute about patient pain. Family caregivers in this study noted discrepancies between expressed pain and reported pain among patients, suggesting that standard assessments of patient pain should include the perspective of the caregiver. As our data illustrate, this is particularly important when family members share the caregiving role or when the patient has Alzheimer's disease or dementia. Caregiver assessment should take into consideration the family system, and future intervention research should consider a family-based approach as opposed to a sole focus on the primary caregiver. 
Findings from this study also demonstrate that family caregivers experience a variance of stress from the caregiving experience, yielding different information and support needs. Most notably, there are varying needs between at-home caregivers and caregivers of loved ones in formal care settings (e.g., nursing home, adult family home). Consistent with prior literature, family members providing care in the home need information and knowledge to handle primary care tasks and reduce primary stress (Lau et al., 2010). In addition, our data demonstrate that caregivers who do not provide primary care have dissimilar needs that emphasize support from the hospice team in obtaining clinical information from care institutions. To summarize, at-home caregivers need knowledge and information about primary care as well as emotional support, and caregivers who do not provide primary care need more support with less emphasis on information.

\section{Conclusion}

Although caregiver health has the strongest relationship with cumulative strain, caregiver appraisal of strain is a risk factor for higher strain (Townsend, Ishler, Shapiro, Pitorak, \& Matthews, 2010). By taking into account stress appraisals of the caregiving experience, as proposed by the ACT model and described in this study as primary, secondary, and intrapsychic stressors, the team can customize interventions specific to the caregiving experience. For example, caregivers with primary stressors as most formidable to their caregiving experience would likely benefit from a coping skills intervention, which has been found to improve caregiver quality of life and reduce the burden related to patients' symptoms (McMillan et al., 2006). Targeted interventions can help staff prioritize the agency's resources to attend to caregivers with greatest needs, and such customized services can result in a reduction in the use and amount of hospice respite benefits while at the same time decreasing caregiver stress (Empeño, Raming, Irwin, Nelesen, \& Lloyd, 2011; Townsend et al., 2010). As this study and others have shown, caregivers have different caregiving experiences that yield specific needs rather than a global caregiver intervention (Lunney et al., 2003).

This study has shown that hospice family caregivers are central to the success and quality of hospice patient care. Caregivers have unique needs that can vary depending on their own psychosocial and physical profile and background. The analyses presented here further evidence the need to assess caregivers for team interventions, although it is limited by the homogeneity of a White sample of hospice caregivers. The study is also limited by the analysis of secondary data from a larger project focused on problem solving.

Of the limited number of studies on caregiver intervention research, the focus has included pain-management knowledge and practice, using technology for communication and education, and one-on-one training about coping and problem solving (Demiris et al., 2010; Keefe et al., 2005; Kutner et al., 2009; Kwak et al., 2007; Lau et al., 2010; MacDonald, 1998; McMillan et al., 2006; Parker Oliver, Demiris, Wittenberg-Lyles, Porock, Collier, \& Arthur, 2010). This study demonstrates that more research is needed in all of these areas and identifies important directions for future intervention development. To start, hospice teams should develop caregiver assessment to capture variance in stress. Caregiver assessment should consider primary stressors (e.g., a rating of how well the caregiver can administer pain medication at home; a rating for how confident the caregiver is when administering pain medication), secondary stressors (e.g., What are family communication practices like? Does the entire family appear to be informed about the patient's prognosis? What level of family involvement and support does the caregiver have?), and intrapsychic stressors (e.g., Is the caregiver able to freely express emotions to staff? To the patient? What self-identified role expectations does the caregiver have? Are they realistic given their support and home infrastructure?). During team discussions, caregiver assessment information should be 
shared to develop care plans that include the caregiver with specificity to the caregiver's needs. Future work is needed to develop standardized instruments and observational tools for hospice providers so they can start assessing caregivers.

\section{Acknowledgments}

\section{Funding}

The authors disclosed receipt of the following financial support for the research, authorship, and/or publication of this article: Funding was received through the NIH National Institute of Nursing Research Grant No. R21 NR010744-01.

\section{References}

Bee PE, Barnes P, Luker KA. A systematic review of informal caregivers' needs in providing homebased end-of-life care to people with cancer. Journal of Clinical Nursing. 2009; 18:1379-1393. JCN2405[pii]. 10.1111/j.1365-2702.2008.02405.x [PubMed: 18624779]

Centers for Medicare and Medicaid Services. Medicare and Medicaid programs: Hospice conditions of participation (42 CFR § 418). Washington, DC: Government Printing Office; 2008.

Chen H, Haley WE, Robinson BE, Schonwetter RS. Decisions for hospice care in patients with advanced cancer. Journal of the American Geriatrics Society. 2003; 51:789-797. [PubMed: 12757565]

Creswell, JW. Qualitative inquiry and research design: Choosing among five traditions. Thousand Oaks, CA: Sage; 1998.

Demiris G, Parker Oliver D, Washington K, Fruehling L, Haggarty-Robbins D, Doorenbos A, Berry D. A problem solving intervention for hospice caregivers: A pilot study. Journal of Palliative Medicine. 2010; 13:1005-1011. [PubMed: 20649438]

Demiris G, Parker Oliver D, Wittenberg-Lyles E. Assessing caregivers for team interventions (ACT): A new paradigm for comprehensive hospice quality care. American Journal of Hospice and Palliative Medicine. 2009; 26:128-134. [PubMed: 19116302]

Demiris G, Parker Oliver D, Wittenberg-Lyles E, Washington K, Doorenbos A, Rue T, Berry D. A noninferiority trial of a problem-solving intervention for hospice caregivers: In person versus videophone. Journal of Palliative Medicine. 201210.1089/jpm.2011.0488

DuBenske LL, Wen KY, Gustafson DH, Guarnaccia CA, Cleary JF, Dinauer SK, McTavish FM. Caregivers' differing needs across key experiences of the advanced cancer disease trajectory. Palliative \& Supportive Care. 2008; 6(3):265-272. S1478951508000400[pii]. 10.1017/ S1478951508000400 [PubMed: 18662420]

Eggly S, Penner LA, Greene M, Harper FW, Ruckdeschel JC, Albrecht TL. Information seeking during "bad news" oncology interactions: Question asking by patients and their companions. Social Science \& Medicine. 2006; 63:2974-2985. S0277-9536(06)00371-6[pii]. 10.1016/j. socscimed. 2006.07.012 [PubMed: 16962218]

Empeño J, Raming NT, Irwin SA, Nelesen RA, Lloyd LS. The hospice caregiver support project: Providing support to reduce caregiver stress. Journal of Palliative Medicine. 2011; 14:593-597. [PubMed: 21438707]

Goldstein NE, Concato J, Fried TR, Kasl SV, Johnson-Hurzeler R, Bradley EH. Factors associated with caregiver burden among caregivers of terminally ill patients with cancer. Journal of Palliative Care. 2004; 20:38-43. [PubMed: 15132075]

Gonyea JG, Paris R, de Saxe Zerden L. Adult daughters and aging mothers: The role of guilt in the experience of caregiver burden. Aging \& Mental Health. 2008; 12:559-567. 904092285[pii]. 10.1080/13607860802343027 [PubMed: 18855171]

Harding R, Higginson IJ. What is the best way to help caregivers in cancer and palliative care? A systematic literature review of interventions and their effectiveness. Palliative Medicine. 2003; 17:63-74. [PubMed: 12597468]

Hebert RS, Schulz R. Caregiving at the end of life. Journal of Palliative Medicine. 2006; 9:11741187.10.1089/jpm.2006.9.1174 [PubMed: 17040156] 
Hudson PL, Remedios C, Thomas K. A systematic review of psychosocial interventions for family carers of palliative care patients. BMC Palliative Care. 2010; 9:17. 1472-684X-9-17[pii]. 10.1186/1472-684X-9-17 [PubMed: 20687960]

Keefe FJ, Ahles TA, Sutton L, Dalton J, Baucom D, Pope MS, Scipio C. Partner-guided cancer pain management at the end of life: A preliminary study. Journal of Pain and Symptom Management. 2005; 29:263-272. [PubMed: 15781177]

Kimberlin C, Brushwood D, Allen W, Radson E, Wilson D. Cancer patient and caregiver experiences: Communication and pain management issues. Journal of Pain and Symptom Management. 2004; 28:566-578. [PubMed: 15589081]

Kramer BJ, Kavanaugh M, Trentham-Dietz A, Walsh M, Yonker JA. Predictors of family conflict at the end of life: The experience of spouses and adult children of persons with lung cancer. Gerontologist. 2009; 50:215-225. gnp121[pii]. 10.1093/geront/gnp121 [PubMed: 19671660]

Kutner J, Kilbourn KM, Costenaro A, Lee CA, Nowels C, Vancura JL, Keech TE. Support needs of informal hospice caregivers: A qualitative study. Journal of Palliative Medicine. 2009; 12:11011104. [PubMed: 19764830]

Kwak J, Salmon JR, Acquaviva KD, Brandt K, Egan KA. Benefits of training family caregivers on experiences of closure during end-of-life care. Journal of Pain and Symptom Management. 2007; 33:434-445. [PubMed: 17397704]

Lau DT, Berman R, Halpern L, Pickard AS, Schrauf R, Witt W. Exploring factors that influence informal caregiving in medication management for home hospice patients. Journal of Palliative Medicine. 2010; 13:1085-1090. [PubMed: 20836633]

Levine C, Halper D, Peist A, Gould DA. Bridging troubled waters: Family caregivers, transitions, and long-term care. Health Affairs. 2010; 29:116-124. 29/1/116[pii]. 10.1377/hlthaff.2009.0520 [PubMed: 20048369]

Lindlof, T.; Taylor, B. Qualitative communication research methods. 2. Thousand Oaks, CA: Sage; 2002.

Lorenz KA, Asch SM, Rosenfeld KE, Lui H, Etter SL. Hospice admission practices: Where does hospice fit in the continuum of care. Journal of the American Geriatrics Society. 2004; 52:725730. [PubMed: 15086652]

Lunney JR, Lynn J, Foley DJ, Lipson S, Guralnik JM. Patterns of functional decline at the end of life. Journal of the American Medical Association. 2003; 289:2387-2392.10.1001/jama.289.18.2387 [PubMed: 12746362]

MacDonald G. Massage as a respite intervention for primary caregivers. American Journal of Hospice and Palliative Care. 1998; 15:43-47. [PubMed: 9468978]

McMillan SC, Small BJ, Weitzner M, Schonwetter R, Tittle M, Moody L, Haley WE. Impact of coping skills intervention with family caregivers of hospice patients with cancer: A randomized clinical trial. Cancer. 2006; 106:214-222. [PubMed: 16329131]

McNamara B, Rosenwax L. Which carers of family members at the end of life need more support from health services and why? Social Science \& Medicine. 2010; 70:1035-1041. S0277-9536(09)00845-4[pii]. 10.1016/j.socs cimed.2009.11.029 [PubMed: 20116158]

Meyers JL, Gray LN. The relationships between family primary caregiver characteristics and satisfaction with hospice care, quality of life, and burden. Oncology Nursing Forum. 2001; 28:7382. [PubMed: 11198900]

National Cancer Institute. Grief, bereavement, and coping with loss (PDQ $\left.{ }^{\circledR}\right)$. Bethesda, MD: Author; 2011. Retrieved from http://cancer.gov/cancertopics/pdq/supportivecare/bereavement/ HealthProfessional

National Hospice and Palliative Care Organization. NHPCO facts and figures: Hospice care in America. Alexandria, VA: Author; 2010.

Parker Oliver D, Demiris G, Wittenberg-Lyles E, Porock D. The use of videophones for patient and family participation in hospice interdisciplinary team meetings: A promising approach. European Journal of Cancer Care (Engl). 2010; 19:729-735. xECC1142[pii]. 10.1111/j. 1365-2354.2009.01142

Parker Oliver D, Demiris G, Wittenberg-Lyles E, Porock D, Collier J, Arthur A. Caregiver participation in hospice interdisciplinary team meetings via videophone technology: A pilot study 
to improve pain management. American Journal of Hospice and Palliative Care. 2010; 27:465473. [PubMed: 20299692]

Parker Oliver D, Wittenberg-Lyles EM, Demiris G, Washington K, Day M, Porock D. Barriers to pain management: Caregivers perception and pain talk by hospice interdisciplinary teams. Journal of Pain and Symptom Management. 2008; 36:374-382. [PubMed: 18495415]

Pearlin LI, Mullan JT, Semple SJ, Skaff MM. Caregiving and the stress process: An overview of concepts and their measures. Gerontologist. 1990; 30:583-594. [PubMed: 2276631]

Pruchno RA, Burant CJ, Peters ND. Typologies of caregiving families: Family congruence and individual well-being. Gerontologist. 1997; 37:157-167. [PubMed: 9127972]

QSR International. NVivo: Version 8 [Computer software]. Doncaster, Australia: Author; 2008.

Rivera HR. Depression symptoms in cancer caregivers. Clinical Journal of Oncology Nursing. 2009; 13:195-202. R57KP045420W8117[pii]. 10.1188/09.CJON.195.202 [PubMed: 19349266]

Sherman DW. Reciprocal suffering: The need to improve family caregivers' quality of life through palliative care. Journal of Palliative Medicine. 1998; 1:357-366.10.1089/jpm.1998.1.357 [PubMed: 15859854]

Stajduhar KI, Nickel DD, Martin WL, Funk L. Situated/being situated: Client and co-worker roles of family caregivers in hospice palliative care. Social Science \& Medicine. 2008; 67:1789-1797. [PubMed: 18922609]

Strauss, A. Qualitative analysis for social scientists. Cambridge, UK: Cambridge University Press; 1987.

Swanberg JE. Making it work: Informal caregiving, cancer, and employment. Journal of Psychosocial Oncology. 2006; 24:1-18. [PubMed: 17088239]

Thielemann P. Educational needs of home caregivers of terminally ill patients: Literature review. American Journal of Hospice and Palliative Care. 2000; 17:253-257. [PubMed: 11883801]

Townsend AL, Ishler KJ, Shapiro BM, Pitorak EF, Matthews CR. Levels, types, and predictors of family caregiver strain during hospice home care for an older adult. Journal of Social Work in End-of-Life \& Palliative Care. 2010; 6:51-72. [PubMed: 20544477]

Wittenberg-Lyles E, Thompson S. Understanding enrollment conversations: The role of the hospice admissions representative. American Journal of Hospice and Palliative Care. 2006; 23:317-322. 23/4/317 [pii]. 10.1177/1049909106289077 [PubMed: 17060296]

Zhang AY, Zyzanski SJ, Siminoff LA. Differential patient-caregiver opinions of treatment and care for advanced lung cancer patients. Social Science \& Medicine. 2010; 70:1155-1158. S0277-9536(10)00044-4[pii]. 10.1016/j. socscimed.2009.12.023 [PubMed: 20137849]

\section{Biographies}

Elaine Wittenberg-Lyles, $\mathrm{PhD}$, is an associate professor at the Markey Cancer Center and in the Department of Communication at the University of Kentucky, Lexington, Kentucky, USA.

George Demiris, $\mathrm{PhD}$, is an associate professor in biobehavioral nursing and health systems at the University of Washington, Seattle, Washington, USA.

Debra Parker Oliver, MSW, PhD, is an associate professor in the Curtis W. and Ann H. Long Department of Family and Community Medicine at the University of Missouri, Columbia, Missouri, USA.

Karla Washington, MSW, PhD, is an assistant professor in the Kent School of Social Work at the University of Louisville, Louisville, Kentucky, USA.

Stephanie Burt, MS, completed her master's degree in communication studies at the University of North Texas, Denton, Texas, USA. 
Sara Shaunfield, MS, is a doctoral student in the Department of Communication at the University of Kentucky, Lexington, Kentucky, USA. 


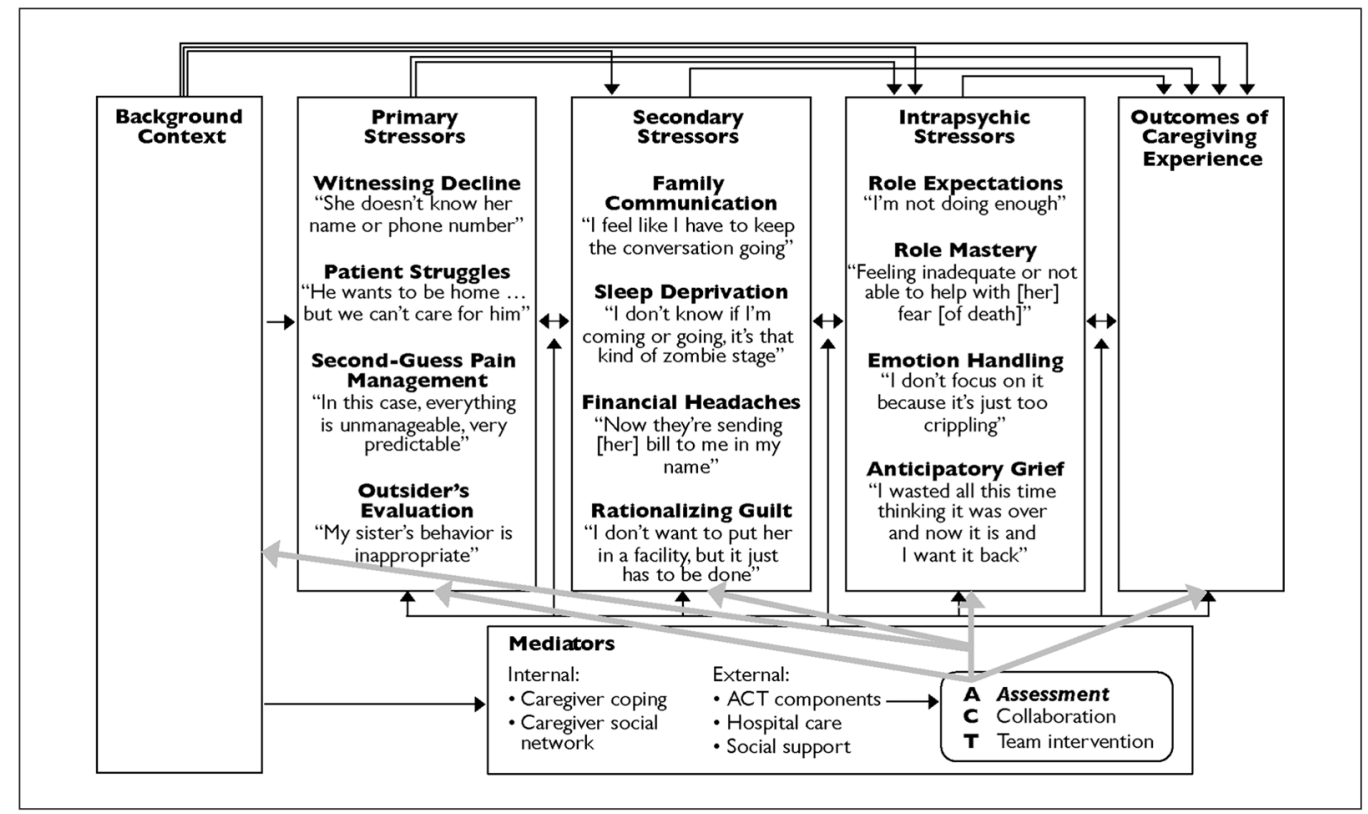

Figure 1.

The ACT model as a mediator within the caregiving experience

Based on a redesign and expansion of the original framework. ACT $=$ assessing caregivers for team interventions. 